\title{
Formação inicial e a manifestação dos acadêmicos sobre a relação teoria prática
}

\author{
Susana Soares Tozetto*
}

Thais de Sá Gomes**

\section{Resumo}

A teoria é entendida na percepção de Otaviano Pereira como a interiorização da prática, contemplaçáo da ação prática. Pautado no conceito do referido autor, buscou-se investigar qual o conceito de teoria na percepção das acadêmicas do curso de Pedagogia, a fim de identificar nos depoimentos das mesmas, indícios que retratem qual a relação teoria/prática entendida. Assim, procura-se identificar nos depoimentos das acadêmicas qual é o entendimento de teoria que elas apresentam e se o mesmo indica a compreensão da unidade da relação teoria e prática, aspecto que possibilitará a práxis. O que se identificou com a investigação foi que em determinado momento do curso as acadêmicas compreendem a teoria separada da prática. Como resultado da investigaçáo percebeu-se que somente um pequeno grupo de acadêmicas demonstraram compreensão do referido conceito, pois retratam em seus discursos o movimento dialético na fundamentação teórico/prática.

Palavras-chave: Formação de Professores. Teoria. Prática.

*Doutora em Educaçáo Escolar pela Universidade Estadual Paulista Júlio Mesquita Filho (UNESP). Professora do Departamento de Educaçáo e do Programa de Pós-Graduaçáo em Educação na Universidade Estadual de Ponta Grossa (UEPG).

** Mestre em Educação pela Universidade Estadual de Maringá (UEM). Professora da Universidade Estadual do Norte do Paraná (UENP). 


\section{Introdução}

Com o objetivo de refletir sobre a dicotomia entre teoria e prática, historicamente estabelecida pela visão da racionalidade técnica nos cursos de formação de professores, nos propusemos a questionar alunas do terceiro ano do curso de Pedagogia, sobre sua percepção em relação à teoria. Na disciplina de estágio do referido curso foi perguntado às acadêmicas como elas entendem o conceito de teoria a fim de compreender pelo viés marxista da dialética como está se construindo tal conceito entre as futuras pedagogas.

A perspectiva marxista envolve o conhecimento do objeto, o estabelecimento de finalidades e a intervenção no objeto para que a realidade seja transformada enquanto realidade social. É a intencionalidade proposta por Marx que irá conferir à prática um caráter diferente. A intenção e a ação de transformar a realidade, presentes na prática, conferem a essa atividade humana a relaçâo teoria e prática para a transformação da natureza e da sociedade. Nesse contexto, a atuação docente não pode ser mecânica, deve ser interativa e ocorrer num movimento dialético, com base nos conhecimentos e saberes que possui.

A preocupação com a relação entre teoria e prática pedagógica tem permeado as discussóes nos cursos de formação inicial de docentes. A relação teoria/prática não é um tema recente. Uma breve análise dessas discussóes permite dizer que apesar dos cursos de formação inicial, de maneira geral, afirmarem unanimemente que a construção da práxis é objetivo a ser atingido ao longo do curso percebe-se uma tendência de enfatizar a teoria em detrimento da prática. Ou ainda, a construção de conhecimentos teóricos e práticos de forma segregada, concebendo que tais conhecimentos são coisas distintas.

Assim, neste artigo, buscamos identificar nos depoimentos das futuras professoras qual é o entendimento de teoria que elas apresentam e se o mesmo indica a compreensão da unidade da relação teoria e prática, aspecto que possibilitará a práxis.

\section{Revendo a concepção de atividade teórica}

Há alguns séculos o conhecimento vem se tornando fundamental para a evolução da humanidade a qual tem sido movida primordialmente pela ciência. Frente as descobertas científicas há uma tendência em ver o mundo de maneira diferenciada. $\mathrm{O}$ mundo moderno se instaura com uma condição 
essencial, que segundo Gimeno Sacristán (1999), reside no entendimento do valor dignificador da cultura acessível para todos. Assim, passamos a valorizar o conhecimento científico - a ciência como base de todas as ações do homem, oferecendo igualdade de oportunidades.

Gimeno Sacristán (1999), afirma que na sociedade moderna a pessoa nãoculta fica excluída, impede-se a participação plena em condiçóes de igualdade. Nesse sentido, esse autor afirma que através da educação podemos construir um caminho para o exercício igualitário da cidadania, oferecendo uma dimensão intelectual para o entendimento do mundo.

A educação dos membros da sociedade é uma condição tanto para o progresso desta quanto para integraçáo daqueles. A educação socializa não apenas reproduzindo, quando transmite conhecimentos, valores e normas de conduta, mas também produzindo laços com o mundo, à medida que habilita para ser e entender-se como um membro dele. (GIMENO SACRISTAN, 1999, p. 154).

Portanto, necessitamos da escola para assinalar a participação de todos no mundo atual. A escola passa a ser uma das instituiçóes sociais responsáveis pela atitude crítica dos sujeitos no contexto em que vivem. Tomando a escola como espaço social que oportuniza a sistematização e a transmissão do conhecimento, com a funçáo política e social passa a ser um fator decisivo e diferenciador entre os seres humanos como referência para o exercício da cidadania.

A escola seleciona e privilegia saberes em detrimento de outros, sendo o professor o sujeito responsável por essa atividade. Sendo assim, o que marca o trabalho docente são: o conhecimento, os seus saberes que são adquiridos, entre outros, através da formaçáo inicial no estudo das teorias educacionais. Seguindo indicações de Gimeno Sacristán (1999), os professores não têm uma atitude passiva frente ao conhecimento, pois está inclusa uma ação transformadora no papel do mesmo. Este profissional assume responsabilidades pelo ensino, pela formação de propósitos nos alunos, sendo que tudo está atrelado às questóes de poder e controle que o conhecimento científico proporciona.

Todas as questôes mencionadas enquadram-se entre convergências e divergências no processo de formação inicial do profissional da educação. $\mathrm{O}$ processo de ensino requer o domínio do conhecimento a ser ensinado e de como se ensina. Para tanto se faz necessário o estudo de teorias e o entendimento das 
mesmas nos cursos de formação de docentes. A teoria entendida como uma síntese aceita de um vasto campo de conhecimento, consistindo de hipóteses que foram devidamente testadas, constituindo-se de leis e fatos científicos.

O processo de gestação e criação do ato de conhecer uma teoria exige estudo, comprometimento, dedicação por parte de quem quer aprender. Dessa forma, conhecer a síntese aceita pela comunidade científica envolve muito esforço por parte de todos.

A teoria explica o fato, e, portanto, deve ser construída a partir dele, ou seja, o fato deve ser estudado e analisado para se constituir em um aparato teórico. O educador é aquele que se baseia nos fatos, observa-os e analisa-os para construir a teoria, formular sua hipótese e fundamentar sua prática. Uma teoria não é expressão pura da realidade, mas uma percepção dessa realidade para ser analisada e compreendida. Teoria não é uma questão de pensamento abstrato, teorizar não significa somente abstrair (PEREIRA, 1994). É preciso perceber que ao observar e analisar o real há um encontro da teoria com a prática construída por aquele que fez a observação e a análise. Por isso, entendemos que a teoria é continuamente construída e reconstruida.

O esforço intelectual para compreender a realidade é pensamento abstrato e por si só não se configura em teoria. Segundo Pereira (1994), é necessário a análise e compreensão da realidade somado ao ato da abstraçấo intelectual para resultar em teoria. Então, teorizar é uma ação complexa, contínua que está vinculada a um fenômeno observado, analisado, mas também, não é resultado de um experimento. E é por isso que falar em teoria é um campo escorregadio.

Sobre o caráter investigativo envolvido na atividade teórica e, portanto, na construçâo da teoria enquanto conhecimentos científicos e saberes acumulados, destacamos que o papel das teorias é oferecer instrumentos e esquemas para análise e investigação que permitam questionar as práticas e as açóes dos sujeitos e, ao mesmo tempo, colocá-las em questionamento, uma vez que as teorias são explicaçôes sempre provisórias da realidade.

Pereira (1994) coloca que não podemos nos apoiar totalmente nos modelos, sem construir nossos próprios caminhos. "Dessa forma, a elaboração teórica que parte do objeto observado nas ciências humanas - no caso o próprio homem em questáo - vai sempre dependendo de modelos de pensamento ou escola" (PEREIRA, 1994, p. 62). O educador assume o papel de criador e criatura nesse processo, pois ao mesmo tempo que elabora sua teoria, teoriza aquela já criada. 
A atividade teórica possibilita de modo indissociável o conhecimento da realidade e o estabelecimento de finalidades para sua transformação. Mas para produzir tal transformação não é suficiente apenas a atividade teórica, é preciso atuar praticamente. Para Vasquez (1977), a relaçáo entre pensamento e fatos requer planejamento, uma vez que a finalidade imediata da atividade teórica é transformar a realidade. No entanto, a transformação por meio da atividade teórica acontece somente no plano ideal e, para que a mesma se efetive realmente, faz-se necessário elevado grau de consciência. Consciência no sentido de se apropriar do conhecimento presente na atividade teórica para transformar as ideias em açóes reais. O autor ressalta que "[...] uma teoria é prática na medida em que se materializa, através de uma série de mediaçóes, o que antes só existia idealmente como conhecimento da realidade ou antecipação ideal de sua transformaçáo" (VASQUEZ, 1977, p. 207).

O papel da atividade teórica é oferecer aos professores perspectivas de análise para compreender os contextos históricos, sociais, culturais, organizacionais e de si mesmos como profissionais, nos quais se dáo suas atividades docentes, para neles intervir, transformando-os. Nesse sentido, é fundamental o permanente exercício da reflexão critica as condiçóes materiais nas quais o ensino ocorre.

Tal reflexão tem como intenção relacionar as açóes de ensino e as de aprendizagem na constituição da atividade pedagógica, não perdendo de vista a dimensão teórica e prática presente na atuação do educador, que se fundamenta na necessidade de humanização dos indivíduos. Isto é, o professor analisa a realidade e as condiçôes postas a partir das informações e conhecimentos obtidos no contexto escolar, organiza objetivamente os meios de atuação, segundo a finalidade da educaçáo, e atua de forma consciente para se materializar na construção do objeto da atividade de ensino.

Contudo, a atividade teórica que extrapola o conhecimento da realidade e se efetiva em açōes reais e concretas de transformação do mundo é, para Vasquez (1977), a práxis. Esta unidade indissolúvel entre teoria e prática que pressupóe consciência individual e coletiva para se apresentar como atividade humana que transforma o mundo e o próprio homem.

O profissional da educação deve ter compreensão do conhecimento em suas múltiplas dimensóes, capaz de construir seu pensamento e sua ação voltados às necessidades de seu cotidiano. Compreender dessa forma a ação pedagógica é negar as tradicionais formas de ensinar, que faz uso da decoreba, 
da repetição. Entretanto, sem uma fundamentação teórica, que é essencial, o professor não tem acesso às discussões mais profundas sobre a situação social da educação, levando-o à alienação, e ao descomprometimento com os problemas que enfrentamos na escola.

A partir dessas consideraçóes, Gimeno Sacristán (1999, p. 26) afirma:

[...] o possuidor da teoria sente-se mais legitimado para falar, para elaborar, para preencher e para dirigir esse projeto instruindo os demais; não se impóe, mas sua superioridade será mostrada no diálogo. Nesse sentido, a ciência se constitui num dos pilares básicos da modernidade; sua posse dotou de legitimidade - poder da razão- àqueles que dela dispuseram frente aos que não a possuíam.

Essa forma de pensar converge com um professor possuidor de uma teoria que sustenta suas açôes, sendo que as mesmas são coerentes com suas perspectivas epistemológicas. A razão - racionalidade - é a fonte primeira do trabalho docente, e a formaçáo inicial, como uma das etapas do desenvolvimento profissional do professor, é responsável por oportunizar a aquisição do conhecimento científico.

\section{A formação Inicial}

É inegável a necessidade do compromisso da escola e de seus professores com o enfrentamento das desigualdades através da democratização dos conhecimentos que minimamente permitirão aos educandos participar, da melhor forma possível, da vida social e produtiva. Assim, o improviso ou espontaneísmo náo correspondem às necessidades da escola hoje, pois, formar um sujeito atuante na sociedade ao qual esta inserida, exige planejamento e compromisso, implicando em estudo e dedicação por parte de quem ensina.

Entender o ato de educar de maneira simplista, sem superar a dicotomia teoria/prática, escola/vida, é a proposta que repudiamos. Dessa forma, é necessário identificar o educador como agente social, com consciência forjada na relação da prática com a teoria, que reconheça o seu papel histórico, bem como a possibilidade de criar e modificar sua ação pedagógica com objetivos reais (GIMENO SACRISTÁN, 1999). Sendo que a teoria deverá oferecer 
perspectivas de análise do contexto ao qual o docente está imerso, e a prática proporcionará experiências concretas em constante processo de reelaboração. Portanto, o docente não se reduz a função de transmissão dos conhecimentos, e sim a problematização da realidade.

Diríamos que para atender a esse contexto esperamos intelectuais críticos e possuidores de compreensão da complexidade das relaçóes de sala de aula. Profissionais que se fundamentem na investigação, nos saberes oriundos da formação profissional e de saberes disciplinares, curriculares e experienciais (TARDIF; LESSARD, 2005). Necessitamos de educadores que tomem a investigação como ação fundamental em suas práticas, aprendendo a pesquisar e questionar continuamente o contexto em que estáo inseridos, ampliando o significado do diagnóstico da realidade para um conhecimento real do campo social que estão atuando.

Assim posto, se faz necessária uma formação inicial consistente, não abrindo espaço para qualquer sujeito ensinar na escola, mas profissionais que se reconheçam como tal, possuidores de um saber próprio, um conhecimento específico necessário para exercer a docência. Dessa forma, fica claro que a profissáo do professor está envolta de conhecimento profissional ligado a uma constelação de saberes de vários tipos, passíveis de uma fundamentação teórica científica, didática e pedagógica (GIMENO SACRISTÁN, 1999).

O professor necessita de uma sólida formação, calcada em uma racionalidade que busca uma análise crítica da realidade ao qual a escola está inserida. Na vida profissional identificamos momentos de aprendizagem que tem influencia direta na qualidade de seu ensino, sendo a formação inicial um desses períodos de importância fundamental. Moraes, Pacheco e Evangelista (2003, p. 76), ressaltam a importância da formaçáo inicial:

No campo específico da formação de professores é preciso aprofundar relaçôes entre a base epistemológica dos currículos dos cursos de formação e a contingência profissional do magistério, levando em conta a base material da sua produçáo. É visível a interferência dessa dimensão, tanto no perfil cultural dos cursos e dos estudantes, como na prática profissional que se institucionaliza. A formação precisa incorporar reflexôes sobre o contexto sócio-político-econômico da produção do magistério como profissão para melhor entender as 
contradições presentes na configuração curricular. Com isso não se está assumindo uma posição estruturalista e conformista. Procura-se, antes, entender os processos e amarras no campo político e epistemológico para lidar com elas no campo pedagógico no sentido de fazer avançar a possibilidade de formação.

A formação inicial de professores é um período crítico e, sem dúvida, um espaço propício para desafios, conhecimentos, experiências de aprendizagem e de ensino. É um momento privilegiado para romper com a reprodução, ou seja, ensinar como foi ensinado. A interrupção da lógica reprodutiva gera um projeto de formação inicial para professores crítico, consistente teoricamente, bem fundamentado, com conteúdos oriundos das teorias da educação. Organizar a formação de professores de acordo com uma perspectiva crítica envolve uma matriz cognitiva que não está a serviço do mercado e sim de uma teoria que apreende e se envolve em uma prática determinada por açóes concretas, reais.

De todo modo, tais questóes transcendem o empirismo, a simples descrição da realidade e busca uma análise balizada no debate filosófico, sociológico, político e histórico. Este é um desafio que temos que enfrentar nos projetos dos cursos de formação de professores: não abdicar de uma teoria e de uma prática que possam apreender a realidade concreta em que as escolas estão envoltas. O trabalho profissionalizado do docente é aquele que conta com formação específica, pautada no conhecimento científico e, que oportuniza o domínio de saberes específicos construídos historicamente e difundidos cientificamente. Nesse sentido, concordamos com Moraes, Pacheco e Evangelista (2003, p. 78):

Portanto, a reflexão sobre currículo da formação de professores exige uma nova configuração que incorpore um posicionamento epistemológico que faça rupturas com a visão tradicional da ciência moderna, incorpore a prática no sentido da experiência e se alicerce numa sólida significação teórica.

A formação de professores precisa de sólidas estruturas epistemológicas e uma ligação real com a prática pedagógica vinculada com a escola. É necessário entender que a base da formação desse profissional deve estar envolta com o fenômeno educativo e suas demandas. A formação deve incorporar as teorias 
da educação, um conhecimento sobre a aprendizagem e o ensino, com uma atitude investigativa.

A atuação de um profissional obrigatoriamente se articula com o domínio de conhecimentos específicos. Scalcon (2008) analisa que a profissionalização docente está atrelada ao status, a formação específica e a valorização salarial e para tanto, é necessário:

[...] domínio articulado dos conhecimentos pedagógicos e específicos da área, situados na totalidade dos conhecimentos socialmente produzidos, pautando-se numa concepção de educação que tem no trabalho pedagógico e na docência a sua particularidade e especificidade, remetendo a prática pedagógica à tarefa histórica da educação escolarizada. (SCALCON, 2008, p. 506).

Aqui a formação inicial do profissional da educação se dá mediante a uma tarefa que requer estudo e dedicação ao conhecimento científico. Uma atitude reflexiva com fundamento na racionalidade, em açóes e situaçóes de conflito, evidenciando diversas realidades culturais, sociais, históricas e políticas. Tomamos a teoria como um instrumento do pensamento e o pensamento como um elemento de mediaçáo entre o homem e a possibilidade do conhecimento e de transformação da realidade (MORAES, 2003).

Tudo isso implica considerar o professor como um sujeito histórico e social que possui saberes específicos da profissão. Ser um profissional da educação significa um domínio do conhecimento científico que atenda aos requisitos mínimos para participar da emancipação das pessoas. Seja como for, o ser professor está associado ao trabalho com os conhecimentos, desde o comum ao especializado.

A dimensão cognitiva está presente na ação do docente. Confrontar, analisar, discutir é referência básica na atuação do professor. Nesse sentido, torna-se fundamental que a prática não seja encarada como uma aplicação da teoria e a teoria como iluminadora da ação. Assim, estaremos associados a um ativismo, com predominância das experiências como fonte de saberes aos docentes. Todavia, uma superposiçâo da teoria acaba por impedir um aporte real na ação docente. A relação teoria/prática pode ser percebida no movimento dialético do conhecimento, entre pontos e contrapontos do contexto social, 
político, econômico, histórico vinculados a realidade concreta em que os sujeitos estão inseridos.

\section{A teoria/prática na formação docente}

No contexto atual, diante das inflexôes teóricas e epistemológicas postas, percebemos a necessidade de mudanças nos currículos dos cursos de formação, valorizando o conhecimento científico. O que coloca os fundamentos da educação, sobretudo o estudo permanente como requisito indispensável ao profissional da educação. Almejando, assim, a construção de saberes sólidos e necessários a práxis docente.

Romper com a racionalidade técnica, que prioriza disciplinas teóricas a priori, depois a transposição na prática através dos estágios, não é uma tarefa fácil. Apontar caminhos numa visão consistente teoricamente demanda muito estudo e análise por parte dos responsáveis, permitindo a compreensão de que a teoria e a prática configuram o espaço efetivo da práxis e, portanto, da realidade social e do agir do professor. A atividade de pensar e analisar se tornam inerente ao ofício do professor. O profissional autônomo intelectualmente deve ser uma figura presente na escola. Entretanto, temos diversos e diferentes problemas nas instituiçóes de ensino, o que leva a ausência de um referencial teórico que se articule com a prática.

O que as pesquisas têm nos mostrado é que grande parte dos profissionais da educação, os educadores presentes nas salas de aula que tomam o estudo como base de suas atividades não as fazem livres de intervenções (TOZETTO, 2010). A referência do professor passa a ser o livro, e/ou resultados de pesquisas produzidas fora do contexto, inspira-se nos saberes e conhecimentos que emergiram da ação refletida do outro. Assim, a reflexão não contribui para a solução de seus problemas, que tem peculiaridades próprias de sua ação pedagógica. Chegar à verdadeira práxis exige uma postura de análise e reflexão mediada por discursos reais, coerentes com o cotidiano.

As preocupaçóes com o cotidiano do professor muitas vezes fica oculta, somente reservada para si, ele náo se sente à vontade para partilhar suas 
verdadeiras angústias e necessidades. O processo de ensinar e aprender não são realmente analisados e problematizados, pois a academia dita normas, posturas que são seguidas sem questionamentos. $\mathrm{O}$ conhecimento deveria fornecer uma base segura para que o educador se tornar sujeito de seu próprio trabalho. Entretanto, o pensar sobre seu fazer acaba sendo reservado para si, sem problematizar e/ou discutir. A voz do professor fica calada, reservada para poucos, não alterando sua prática em sala de aula.

O conhecimento acumulado cientificamente é fundamental na tarefa do professor, entretanto não é suficiente. Faz-se necessário a descoberta de instrumentos que levem os docentes à construção de seu próprio saber, para resolver seus próprios problemas. Quando se leva em conta a realidade vivida, as análises tomam por base a realidade concreta, trilha -se um caminho que provoca a verdadeira análise reflexiva.

Sendo assim, concordamos com Imbernón (2010, p. 31) quando coloca:

Diversos autores procuraram analisar o tipo de conhecimentos profissionais que um professor ou uma professora deveriam ter (cf. Schuman, 1989; LoucksHorlev, 1987). Todos eles concordam com a necessidade de um conhecimento polivalente que compreenda diferentes âmbitos: o sistema (em suas estruturas próprias, sintáticas, ideológicas ou em sua organização), os problemas que dão origem à construção dos conhecimentos, o pedagógico geral, o metodológico-curricular, o contextual e o dos próprios sujeitos da educação. Em diversas publicaçôes enfatizei a importância de conhecimentos sobre o âmbito sociocultural e sociocientífico (implicaçôes sociais das ciências), considerando que o contextual referia-se em geral ao âmbito estritamente profissional.

Grande parte dos problemas enfrentados na escola hoje, diz respeito às relaçóes do ensinar e do aprender, ou seja, considera a ação do professor como um dos fatores principais. Sendo o docente, o responsável pela condução do processo ensino aprendizagem, é, portanto, o alvo das discussóes. A formação desse profissional passa a ser de suma importância, pois, a base do conhecimento pedagógico, adquire-se na formação inicial e/ou na formação continuada. Considera-se, assim, que em sua trajetória profissional, o educador constrói e reconstrói seus saberes, conforme a fundamentação adquirida ou não nos momentos da formação. 
$\mathrm{Na}$ formação dos professores a realidade se faz necessário superar a linearidade mecânica posta frente ao conhecimento teórico e ao conhecimento prático. Romper com a dicotomia teoria/prática, e tratar o conhecimento como fonte de recursos intelectuais que subsidiam a ação docente em todos os momentos da prática pedagógica. A aquisição do conhecimento não é um processo mecânico, implica em constante movimento e transformação. Portanto, a formação de professores se articula aos conhecimentos interligados com a própria ação, pois

A reflexão implica a imersão consciente do homem no mundo da sua experiência, um mundo carregado de conotaçôes, valores, intercâmbios simbólicos, correspondências afetivas, interesses sociais e cenários políticos. O conhecimento acadêmico, teórico, científico ou técnico, só pode ser considerado instrumento dos processos de reflexáo se for interligado significativamente, não em parcelas isoladas da memória semântica, mas em esquemas de pensamento mais genéricos activados pelo indivíduo quando interpreta a realidade concreta em que vive e quando organiza a sua própria experiência. (NÓVOA, 1995, p. 103).

A partir dessa proposta é que a formação do professor vai auxiliar na construção da práxis. Podemos vislumbrar um compromisso e um desafio, na luta por uma autonomia intelectual do educador, que o possibilite a atuar como sujeito de sua prática.

Diante dessas preocupaçóes com os conhecimentos desenvolvidos na prática docente, tem-se que considerar que o professor atua para consolidaçáo dos mesmos, sendo necessário tempo, para um favorecimento ao acesso dos fundamentos necessários à aprendizagem da docência. Não há possibilidade de construir uma teoria às cegas, sem conhecer os pontos de referência, sua história, sem participar do processo como um todo. Inicialmente, com o objetivo de confrontar, medir, reforçar, para posteriormente obter uma transformação no trabalho do professor, pois um conhecimento necessita ser apreendido, os docentes precisam ter conhecimento para ter voz, precisam de açôes refletidas e analisadas, pois trata-se de um saber especializado de primeira ordem. 
Cada ação do docente acontece em um tempo, em um lugar, sob determinadas condiçốes e consoante aos atores que dela participam. Entretanto, o ensino exige atitudes rápidas, com um grande cabedal de conhecimento, portanto a aquisiçáo do conhecimento por parte do professor para ensinar, tem que atender a essas necessidades. A atividade docente náo tem nada de simples e natural, é uma atividade profissional que exige formação especializada do professor, reivindica um amplo estudo, implicando dedicação e rigor científico.

No trabalho docente está implícita a interpretação simultânea das ações cotidianas, portanto a autonomia do professor na ação docente não pode ser limitada a ensinar o que prescreve o programa curricular. $\mathrm{Na}$ credencial para ensinar está incluso a cultura, o saber, o estilo de vida, valores e crenças dos professores. Não é apenas uma relação entre aquele que ensina e aquele que aprende, mas uma relação complexa que envolve práticas e situaçóes culturais, sociais, históricas, ética, morais etc. No fazer do dia a dia os professores constroem suas identidades profissionais, dentro de limites e possibilidades concretas, o que implica em reconhecer que ao enfrentar as atividades costumeiras é que nos tornamos professores.

Entretanto, o processo de formaçáo do profissional docente, não se dá pelo acúmulo de conhecimentos ou técnicas, mas através de uma ação concreta, intencional e consciente. $\mathrm{O}$ processo é gradativo e crescente, pois o profissional da docência necessita de uma base maior que a análise de sua experiência. A produção do conhecimento do docente está amparada na experiência, mas não advém somente dela, é necessário empenho, dedicação aos estudos para a conquista de um referencial que atenda às exigências do dia a dia da profissão. (TOZETTO, 2010).

No embate diário o professor tem encontrado problemas para se reafirmar como profissional. As relaçóes cotidianas que essa profissão necessita têm engendrado um emaranhado de saberes evidenciando a importância de se associar a diferentes áreas do conhecimento para dar conta do ato de ensinar. $\mathrm{O}$ docente em seu trabalho tem enfrentado dificuldades, suplementando o saber específico da docência, diante da precarização. Na versão de um novo professor é sugerida uma formação sólida em conteúdos e uma discussão consistente em relação às técnicas. Ao centrar a solução da atuação docente em uma formação compreendida concretamente com suas relaçôes teórico/práticas, assinala-se para um profissional na escola que proporcione a aprendizagem de seus alunos. 


\section{A pesquisa: procedimentos metodológicos}

Optou-se pela abordagem qualitativa de pesquisa que, segundo André (2005, p. 47), trás "[...] o mundo dos sujeitos, os significados que atribuem às suas experiências cotidianas, sua linguagem, suas produçôes culturais e suas formas de interaçóes sociais". Essa abordagem possibilita uma análise do contexto, uma compreensão próxima da realidade e uma interação real com os sujeitos pesquisados.

Dessa forma, decidiu-se pelo delineamento dos sujeitos pesquisados no curso de Pedagogia turma 2010, de uma instituição pública no Estado do Paraná. A presente investigação teve como objetivo conhecer em uma instância particular do referido curso, qual é o entendimento de teoria que as acadêmicas apresentam e se o mesmo indica a compreensão da unidade da relação teoria e prática, aspecto que possibilitará a práxis.

A instituição de ensino superior (IES) pesquisada se localiza na regiáo oeste do Paraná e atende a vários municípios vizinhos, envolve um amplo campo de atuação. A IES é uma Universidade tradicional e conceituada na região em que esta inserida. $\mathrm{O}$ contexto, nesta pesquisa, refere-se à cultura institucional do interior do estado. O grupo de sujeitos envolvidos no processo de formação inicial dessa IES tem contato no estágio supervisionado com a organização do trabalho pedagógico que se rege por normas e formas de escolas pequenas, que atendem alunos advindos de uma classe social desprivilegiada localizada na periferia da cidade.

A primeira fase da investigaçáo foi exploratória. Buscou-se estabelecer uma relação de confiança com as alunas do curso de Pedagogia, na intenção de obter respostas fidedignas às concepçóes de teoria.

A segunda fase foi a elaboração do instrumento de pesquisa que foi o questionário discutindo o conceito de teoria. O questionário foi aplicado com 25 alunas do curso de Pedagogia, que cursavam o terceiro ano. Na presente pesquisa, um dos critérios de escolha do grupo de alunas se deu devido a familiaridade das pesquisadoras com o grupo.

Estabelecidos os contatos iniciais, foi aplicado o questionário com perguntas abertas, que cumpre a função de descrever as características do objeto de pesquisa. Conforme Richardson (1999, p. 195), as perguntas abertas possibilitam ao "[...] entrevistador responder com mais liberdade, náo estando restrito a marcar uma ou alternativa. Isso ajuda muito o pesquisador quando 
ele tem pouca informação ou quer saber um assunto". Ainda segundo o mesmo autor, coloca que esse instrumento de pesquisa também possibilita uma revisão de literatura sobre o tema e a própria experiência do pesquisador.

A intervenção em sala de aula foi marcada com antecedência com as acadêmicas e o professor responsável da turma. Teve a duração de duas horas para que todas as alunas respondessem as questōes. Os dados colhidos através das respostas ao questionário foram analisados, discutidos entre as pesquisadoras e confrontados com o referencial teórico aqui exposto.

\section{A atividade teórica na voz das acadêmicas}

Ao questionar e ser questionado, o professor busca melhorias em sua prática, conquista autonomia e assume responsabilidades para seu desenvolvimento profissional. Ele se forma como sujeito do processo ensino aprendizagem na produção da prática pedagógica, atribuindo sentido a suas açóes em sala de aula através da fundamentação teórica. Para exercer a autonomia pedagógica e o controle do espaço da sala de aula, o docente necessita ser o sujeito de seu próprio trabalho, consciente de suas açóes no contexto, que pensa sobre o trabalho desenvolvido, produz, cria e avalia o processo balizado pelas teorias da educaçáo. Um professor autônomo requer o domínio do processo de ensino e aprendizagem em sua totalidade, desde o planejamento até a avaliação, passando pelo currículo e pelas políticas educacionais.

Sendo assim, o projeto de formaçáo inicial do docente deve buscar uma perspectiva de totalidade, evolvendo a relação teoria / prática em todos os momentos do curso. Essa perspectiva pode ser retratada na opinião de acadêmicas do terceiro ano curso de Pedagogia, que entendem a teoria como uma açáo interna do pensamento que reflete na açáo prática, como podemos ver nas seguintes falas: "Teoria é o planejamento, é o pensar sobre o fazer, é a visäo de como se deve agir, qual hierarquia a ação deve tomar, como deverá ser a ação"; "Teoria se refere ao planejamento, elaboração de uma determinada ação que será realizada".

Percebe-se nas falas das referidas acadêmicas uma relação entre conhecimento (possível teoria) e ação (possível prática) e, nesse sentido, a teoria é entendida como uma ação consciente que só existe na relação com a prática, por isso é flexível e pode ser reelaborada.

Denota-se, portanto, que teoria e prática são processos autônomos e independentes, uma vez que a prática é o fundamento e a finalidade da teoria, 
e a teoria, mesmo que determinada pela prática, a ela se antecipa. É o que Vasquez (1977) denomina de autonomia relativa da teoria. Nesse sentido, ainda temos a fala de mais duas acadêmicas: "Teoria é o estudo realizado e comprovado, utilizado para o planejamento, embasamento de algo a ser realizado"; "E explorar o conhecimento para compreendê-lo, é a base da ação prática".

A teoria vista como uma relaçáo interna do pensamento, da ação que realizamos, que refletimos sobre para depois agir sobre o refletido, entretanto não são açôes díspares. A teoria elaborada e reelaborada a partir de minha prática, ação consciente com caráter de transformação do agir. Assim, a teoria não permanece no abstrato desvinculado da açáo, ela está interligada ao agir.

Pereira (1994, p. 70) coloca que a teoria não se faz no vazio, fora da relação de transformação do contexto real: "[...] a teoria que não se enraíza neste pressuposto não é teoria porque permanece no horizonte da abstração, da conjuntura, porque não ascendeu ao nível da ação". A teoria está sempre fundamentando e se interligando com a ação prática do sujeito e não vem de fora para dentro, ela nasce das relaçóes que estabeleço com a realidade que vivo. É assim que se criam as relaçóes, se estuda uma teoria e ai constrói-se uma prática que está intimamente ligada aos aspectos teóricos. A teoria é interiorizada e reelaborada para posteriormente ser operacionalizada na prática, ela nasce da contemplação da ação prática, é compreendida, apropriada e idealizada, para depois se constituir em ação real com a finalidade de transformação do mundo social e do homem.

Todavia, o conceito de teoria é compreendido pela maioria das acadêmicas (vinte e uma) como ação exterior, um conhecimento que vem de fora para ser aplicado. Um conhecimento acumulado socialmente que adquirimos em livros e aplicamos na prática para solucionar algum problema. O conhecimento é estático e adquirido para iluminar a prática. Nesse sentido, reproduzimos a fala de algumas alunas:

- Teorias são o embasamento, fundamentos que orientam a prática.

- São tratados que estudiosos fizeram para ser testado na prática.

- A teoria é o que aprende nos livros, modos de como fazer, como agir. Conceitos explicados em livros, artigos que só saberemos se dá certo na prática. 
Fica evidente a separação da teoria com a prática. Para se realizar a ação se tem como pano de fundo os conceitos teóricos produzidos por alguém. $\mathrm{O}$ critério de verdade está ligado a um conhecimento produzido pelo outro para somente ser aplicado pelo professor. Náo percebe a teoria como uma produçáo advinda da reflexão e da análise, ela sempre está subordinada aos interesses do outro. O professor só a utiliza, não a produz.

No entendimento de outras acadêmicas, a reflexão, imprescindível para a atividade teórica, é sinônimo de comparação, ou seja, antes da proceder a aplicação da teoria na prática é preciso analisar (e isso se dá superficialmente) qual a teoria que se enquadra melhor àquela situação, como se fosse possível formatar as ações humanas. Isso é evidente na fala das seguintes alunas:

$$
\begin{aligned}
& \text { - Teorias são muitas, mas deve-se escolher a que melhor se } \\
& \text { aplica no processo ensino aprendizagem, considerando sempre } \\
& \text { o melhor para o aluno. } \\
& \text { - Teoria é a base dos conhecimentos, conteúdos científicos que } \\
& \text { é adquirido na graduação, especialização etc. }
\end{aligned}
$$

Tal formatação da prática a teoria, revelada pelas acadêmicas, pressupóe subordinação da prática à teoria. Por conseguinte, há uma concordância em que a teoria vem a priori para sustentar uma prática posterior. A teoria é vista como uma justificação da ação prática "[...] e náo propriamente como esclarecimento e guia de uma práxis que, ao mesmo tempo, fundamenta e enriquece". (VAZQUEZ, 1977, p. 212).

Numa segunda análise, ainda dentro da perspectiva do entendimento de que teoria é algo concebido fora do processo de análise e de reflexão, temos um grupo de alunas que percebe o movimento nesse processo. No ato de conhecer e pensar é possível reconstruir, evoluir. Vejamos então a fala das acadêmicas: "Aquilo que traduz algo que foi pesquisado, experimentado, mas mesmo assim não está pronto e acabado, pode ser mudado, se na prática houver outro resultado"; "[...] uma teoria pode ser questionada, uma vez que tudo é relativo, nada está pronto e acabado".

A partir do momento que se coloca a teoria como inacabada, se tem a dimensão que caminhos foram percorridos, mas há outros a percorrer. Nos aspectos que investigamos a teoria se movimenta, mas ainda está atrelada a um aporte exterior as minhas açôes, ou seja, está em outro patamar que não 
a reflexão e análise do próprio professor. A teoria ainda não deixa de ser um momento da abstração isolado da prática (PEREIRA, 1994).

As acadêmicas ainda colocam que teoria é:

- Como ideias que podem ser questionáveis, mas que têm argumentos que as aproximam da verdade.

- A teoria é o resultado de uma pesquisa, estudo, investigação acerca dos fenômenos que interferem ou não na vida cotidiana, não se apresenta de forma acabada, ela pode ser modificada a partir de nossos estudos.

O ato de conhecer e pensar, nessa visão, ainda é mecânico, não estabelece relaçáo com reflexão e análise, mas já admite um diálogo com outras dimensóes. Dessa forma, é possível perceber que a teoria transforma a ação, porém, não a produz. O significado da ação pedagógica náo estabelece relaçáo com a teoria, é como se a teoria, produzida por outro, somente fosse aplicada na prática. A importância da teoria fica em segundo plano, pois ela vem de fora para dentro e seu sentido e significado ficam fragmentados. Gimeno Sacristán (1999, p. 41) coloca que é "[...] preciso incidir no significado da ação pedagógica, com sentido para os sujeitos, que conecte com os significados, os valores e motivaçóes". A relação teoria/prática é um posicionamento radicalmente interligado ao sentido e ao significado individual, que se atribui na totalidade daquilo que se aprende. O binômio teoria/prática náo se descola do terceiro vértice: o sentido que cada sujeito atribui ao que aprendeu teoricamente.

A preocupação com a relação entre teoria e prática pedagógica tem permeado as discussóes na educação e, principalmente, as que se referem aos cursos de formação inicial. Uma breve análise dessas discussóes permite dizer que, apesar dos cursos de formação inicial, de maneira geral, afirmarem unanimemente que a construção da relação teoria e prática é objetivo a ser atingido ao longo do curso se percebe uma tendência real de enfatizar a teoria em detrimento da prática. Ou ainda, a construção de conhecimentos teóricos e práticos de forma segregada, concebendo que tais conhecimentos são coisas distintas.

\section{Considerações Finais}

$\mathrm{O}$ interesse central dessa investigação foi norteado pela preocupação em conhecer o conceito que as alunas do curso de Pedagogia atribuíam a teoria e a relação teoria/prática realizadas no curso. A proposta objetivou 
discutir a aprendizagem das acadêmicas e suas reflexões em sala de aula de um conhecimento sobre a teoria/prática necessário para o entendimento da ação docente na atuação profissional. O estudo sobre o conhecimento que elas obtiveram nesse período envolve trabalho realizado por todos os docentes ao longo do curso e as reflexóes efetuadas nas discussóes em sala de aula.

Percebeu-se que ao se discutir teoria, não basta somente leituras e uma relação forçada pelos exemplos da prática pedagógica, faz-se necessário uma postura investigativa em todos os momentos do curso. As relaçóes que o professor estabelece devem servir para interligar as fontes teóricas que as acadêmicas já possuem em suas experiências com a práxis sobre o trabalho pedagógico. Portanto, o aluno é que tem que perceber as conexões possibilitadas pelos debates realizados no curso, e não esperar que o professor ou alguém faça esse movimento de relação teoria/prática.

$\mathrm{Na}$ presente investigaçáo foi selecionado o discurso das alunas que manifestaram um entendimento sobre o conceito de teoria. Descartamos um grupo pequeno de alunas que demonstraram um entendimento dos fundamentos teóricos e das açóes práticas do trabalho docente, pelo menos no que diz respeito a conceituação, pois cabe lembrar que a investigação se deteve na descrição do conceito de teoria.

Assim, podemos concluir que a investigação deu conta de analisar as manifestaçôes desse grupo de 25 acadêmicas de Pedagogia sobre o conceito de teoria. Pode-se inferir que esse não atende às necessidades requeridas no contexto do curso em questão. Os depoimentos apontam para não há entendimento do conceito de teoria conforme colocam Pereira (1994) e Vazquez (1977), a inclinação que nos leva a essa conclusão advém da maioria dos depoimentos das acadêmicas do curso de Pedagogia. Assim, fica posto um desafio a ser enfrentado no referido curso: romper com a dicotomia teoria/prática. E, talvez, um dos caminhos será deixar claro o conceito do que é teoria e do que é prática. A compreensão dos conceitos citados, segundo este ponto de vista, leva ao entendimento da práxis. 


\section{REFERÊNCIAS}

ANDRÉ, Marli Eliza D. A. Estudo de caso em pesquisa e em avaliação educacional. Brasília: Liberlivros, 2005.

GIMENO SACRISTÁN, José. Poderes instáveis em educaçâo. Porto Alegre: Artmed, 1999.

IMBERNÓN, Francisco. Formação docente e profissional: formar-se para a mudança e a incerteza. São Paulo: Cortez, 2010.

MORAES, Maria Célia Marcondes de. Iluminismo às avessas: produção de conhecimento e políticas de formação docente. Rio de Janeiro: DP\&A, 2003.

MORAES, Maria Célia Marcondes de; PACHECO, José Augusto; EVANGELISTA, Maria Olinda (Org.). Formaçâo de professores: perspectivas educacionais e curriculares. Porto: Editora Porto, 2003.

NÓVOA, Antônio (Org.). Os professores e a sua formação. 2. ed. Lisboa: Publicaçōes Dom Quixote. 1995

PEREIRA, Otaviano. O que é teoria. São Paulo: Brasiliense, 1994.

RICHARDSON, Roberto Jerry. Pesquisa social: métodos e técnicas. São Paulo: Atlas, 1999.

SCALCONS, Suse. O pragmatismo e o trabalho docente profissionalizado. Perspectiva. Florianópolis, SC, v. 26, n. 2, p. 489-521, jun./dez. 2008.

TARDIF, Maurice; LESSARD, Claude. O trabalho docente: elementos para uma teoria da docência como profissáo de interaçóes humanas. Rio de Janeiro: Vozes, 2005.

TOZETTO, Susana Soares. Trabalho docente: saberes e práticas. Curitiba: CRV, 2010.

VAZQUEZ, Adolfo Sánchez. Filosofia da práxis. Rio de Janeiro: Paz e Terra, 1977. 


\section{La formación inicial y la manifestación de los estudiantes sobre la relación entre la teoría y la práctica}

\section{Resumen}

Entendemos en este texto a la teoría en el sentido que el autor Octavio Pereira considera: como la internalización de practica, practica como la contemplación de la acción. Guiados por el concepto de este autor hemos tratado de investigar cómo el concepto de la teoría es entendido por los estudiantes del curso de pedagogía, con el fin de identificar las informaciones de los mismos sobre la relación entre teoría y práctica. Es decir, tratamos de identificar como la teoría se presenta para ellos y que comprensión tienen sobre la unidad de la teoría y la relación práctica. Identificamos con esta investigación que en un determinado momento del curso se comprende la teoría separada de la práctica. Como resultado de la investigación se observó que sólo un pequeño grupo de estudiantes demostraron comprensión del concepto, ya que en sus respuestas expresaron el movimiento dialéctico sobre la relación teórica/práctica.

Palabras claves: Formación del profesorado. Teoría . Práctica.

\section{Initial training and demonstration of academic theory on the relationship practice}

\section{Abstract}

The theory is understood in the sense of Octavian Pereira as internalization of practice, contemplation of practice action. Guided by the concept of this author, we sought to investigate the concept theory in the perception of the students of pedagogy course, in order to identify in their statements, evidences that portray their understanding about the relationship between theory/ practice. Thus, we seek to identify the academics' statements what is their understanding of theory and if it indicates an understanding of the unity of theory and practice relation, which is an aspect that allows the practice. This research identified that at a specific point the course, the academic students understand theory separated from practice. As a result of the investigation it was noticed that only a small group of academic demonstrate understanding of the concept. They portrayed in their speeches the dialectical movement in theoretical/practical reasons.

Keywords: Teacher Training. Theor .

Practice. 


\section{Susana Soares Tozetto}

E-mail: tozettosusana@hotmail.com

Thais de Sá Gomes

E-mail:thaisdesa@bs2.com.br

Recebido em: 7/8/2012

Última versão recebida em: 10/1/2013

Aprovado em: 15/2/2013 